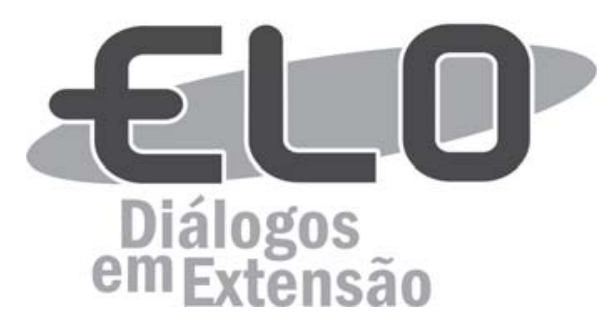

\title{
Técnicas de compostagem desenvolvidas pela horticultura familiar agroecológica
}

\author{
Adalgisa de Jesus Pereira ${ }^{1}$; Felipe Carvalho Santana ${ }^{2}$; \\ Franklin de Jesus Pereira ${ }^{3}$ Ariecha Vieira Rodrigues Tibiriçáa
}

\begin{abstract}
Resumo: A construção do conhecimento tradicional na agricultura ocorreu a partir de relações sociais baseadas no intercâmbio de conhecimento, na troca de sementes e no desenvolvimento de relações tecnológicas mais harmoniosas com o ambiente. As tecnologias sociais e as técnicas usadas pelos agricultores são especialmente importantes entre os horticultores, pois a produção de hortaliças é complexa e exige cuidados diários. Para o conhecimento e socialização das tecnologias desenvolvidas por horticultores familiares, aplicou-se entrevistas semiestruturadas e visitas às propriedades, apurou-se as técnicas desenvolvidas por horticultores agroecológicos da região da Zona da Mata de Minas Gerais. Os resultados demonstraram que, mediante a escassez de recursos financeiros, horticultores agroecológicos desenvolvem formas de compostagem que viabilizam a produção e aproveitam melhor o tempo no campo.
\end{abstract}

Palavras-chave: Inovação. Agricultura Familiar. Desenvolvimento Sustentável. Agroecologia.

Área Temática: Agroecologia. Ruralidade.

\section{Composting Techniques Developed By Horticulture Family Agroecology}

Abstract: The construction of traditional knowledge in agriculture took place based on social relations based on the exchange of knowledge, seeds, and the development of technological relations more harmonious with the environment. The social technologies and techniques used by farmers are especially important among horticulturists, since the production of vegetables is complex and requires daily care. For the knowledge and socialization of the technologies developed by family horticulturists, semi-structured interviews and visits to the properties were applied, the techniques developed by agroecological horticulturists of the Zona da Mata region of Minas Gerais, MG, were determined. The results showed that, due to the scarcity of financial resources, agroecological horticulturists develop composting processes that make production feasible and make better use of the time in the field.

Keywords: Innovation. Family Farming. Sustainable Development. Agroecology.

\section{Técnicas de compostaje desarrolladas en la horticultura familiar agroecológica}

Resumen: La construcción de los conocimientos tradicionales en la agricultura se produjo apartir de las relaciones sociales basadas en el intercambio de conocimientos, cambios de semillas y en el desarrollo de una relación más armónica con el entorno tecnológico. Tecnologías sociales y técnicas utilizadas por los agricultores son especialmente importantes entre los horticultores, visto que la producción vegetal es compleja y requiere cuidado diario. Para el conocimiento y la socialización de las tecnologías desarrolladas por los horticultores familiares, se realizó entrevistas semiestructuradas y visitas a la propiedad, se conferió las técnicas

${ }^{1}$ Doutoranda em Fitotecnia pela Universidade Federal de Viçosa. Endereço: Rua Gama, 85, Viçosa-MG; Telefone: (31)9945-8163; Email: adalgisa.pereira@gmail.com.

${ }^{2}$ Doutorando em Solos e Nutrição de Plantas pela Universidade Federal de Viçosa.

${ }^{3}$ Estudante de graduação em Licenciatura em Educação do Campo pela Universidade Federal de Viçosa.

${ }^{4}$ Geofrága pela Universidade Federal de Viçosa, ariechavrt@gmail.com 
desarrolladas por los horticultores agroecológicas de la región de la Zona da Mata de Minas Gerais. Los resultados mostraron que, por la escasez de recursos financieros, los horticultores agroecológicos desarrollaron formas de compostaje que permiten la producción y mejor disfrutar de su tiempo en el campo.

Palabras clave: Innovación. Agricultura Familiar. Desarrollo Sostenible. Agroecología.

\section{Introdução}

A experiência se torna relevante por lançar luz sobre aspectos da agricultura familiar, dando, à questão, visibilidade social, sobretudo por esta ser responsável pela produção de alimentos livres de contaminação, ou seja, com maior qualidade para consumo (GLIESSMAN, 2009). No entanto, um gargalo existente é a sua produção em quantidade, visto que este tema é alvo de críticas. A despeito das descrenças, pesquisas da ciência tradicional esclarecem essa inverdade, pois agricultores, em sua grande maioria aqueles de organizações familiares, desenvolvem experimentações a fim de viabilizar a produção em qualidade e quantidade. Tais experimentações são perceptíveis desde que o homem começou a domesticar espécies vegetais na intenção de obter uma produtividade cada vez mais alta (FLORIANI e FLORIANI, 2010). Atualmente, isso ainda acontece em detrimento de todo avanço tecnológico que a agricultura acumulou. Assim, para a manutenção dos agroecossistemas produtivos, é importante conhecer o funcionamento de processos ecológicos e de serviços que a natureza disponibiliza, bem como os recursos necessários (COTRIN e DAL SOGLIO, 2010). Logo, a horticultura traz consigo a necessidade de observação do solo, da água e das plantas. Agricultores da horticultura familiar são experimentadores e motivaram o registro neste trabalho; trazem consigo experiências de vida e de cunho prático agronômico que desenvolveram por meio de suas observações pessoais e por meio do aprendizado com seus antepassados.

\section{Objetivos}

Nesse contexto, o relato dessa experiência objetiva resgatar e analisar as práticas agroecológicas desenvolvidas na horticultura familiar de modo a contribuir para a construção do conhecimento agroecológico. Pretende-se, desse modo, identificar, sistematizar de forma participativa e socializar as tecnologias sociais e práticas utilizadas pelos agricultores/as agroecológicos no manejo de suas hortas.

A experiência aqui relatada trata, essencialmente, de valorizar o conhecimento prévio que o horticultor agroecológico demonstrava e praticava em seu cultivo. A descrição e sistematização de técnicas ajustadas, reinventadas e utilizadas na horticultura familiar na Zona da Mata de Minas Gerais podem ser consideradas ações viabilizadoras da horticultura na região. A experiência perpassa pelo desenvolvimento de pesquisa participante, colaborando para a construção do conhecimento agroecológico.

O estudo foi realizado em quatro municípios da região da Zona da Mata Mineira. Foram levantadas e sistematizadas experiências de vinte famílias agricultoras (três famílias em Viçosa, oito em Visconde do Rio Branco, oito em Espera Feliz e uma em Ervália).

A região da Zona da Mata - ou "Matas de Minas" - está inserida no estado de Minas Gerais e abriga o hot-spot de biodiversidade mais ameaçado no Brasil e na América Latina, a Mata Atlântica. O bioma dessa região, atualmente, possui cobertura vegetal restante na ordem de $7 \%$ da mata original (DEAN, 2004; CAMARA, 2005; GOLFARI, 1975). Durante visitas às propriedades rurais foram realizadas entrevistas semiestruturadas, caminhadas pela propriedade - em especial nas áreas de horta e pomar - e observação participante. Ao final da pesquisa foram realizados intercâmbios de devolução dos resultados.

\section{Resultados e discussão}

A compostagem de materiais na agricultura é uma metodologia que contribui para suprir a demanda por adubos orgânicos (LEAL et al., 2013). Para Fialho et al. (2010), estse procedimento estabiliza materiais orgânicos de diferentes origens com concentrações de nutrientes disponíveis. A viabilidade econômica no preparo de adubos orgânicos por meio da compostagem se relaciona, dentre outros fatores, à utilização de matérias-primas em abundância (LEAL et al.,2007). Istso foi observado, nesta pesquisa, quando o agricultor fez a compostagem de mamona, vegetal abundante em sua horta. Nestse caso houve potencialização dos recursos disponíveis. 


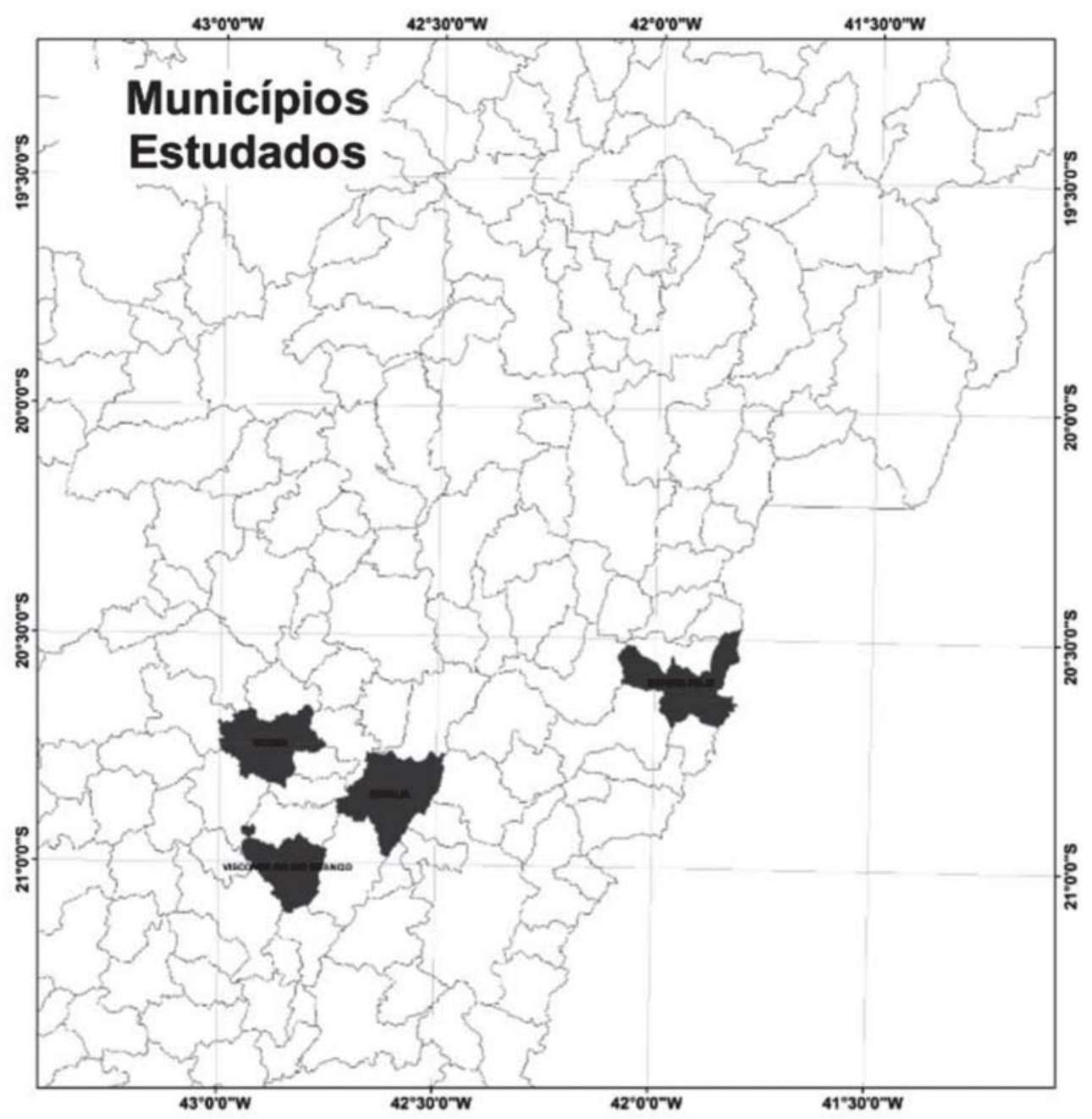

Figura 1 - Mapa com parte dos municípios da Zona da Mata mineira, realçando os municípios de Viçosa, Visconde do Rio Branco, Ervália e Espera Feliz, onde residem as famílias de agricultores(as) que participaram da pesquisa.

Fonte: LabGeo.

A compostagem é importante para o meio ambiente, pois diminui o volume de resíduos sólidos e aumenta a produção de adubos para a agricultura (TEIXEIRA et al., 2002; BEHLING et al., 2011). Os efeitos positivos dos tipos de composto na qualidade do solo estão na modificação das suas propriedades biológicas, físicas e químicas e tem sido alvo de constantes estudos (DIACONO \& MONTEMURRO, 2010). As compostagens aqui descritas, como a multmistura, a espuma do tacho de caldo de cana e a compostagem ao pé da planta, podem ser tomadas como de caráter inovador e de uso local.

\section{Composteira da janela da cozinha}

Segundo um dos agricultores participantes, para facilitar o descarte de restos de alimentos, próximo à janela da cozinha, foi fixada uma base, usada como suporte para um carrinho de mão (Figura 2A). No fundo do recipiente suspenso se adiciona solo, e então, segue-se adicionando os restos gerados na cozinha, que serão, ao fim do processo de compostagem, utilizados na horta.

O material gerado é misturado à terra de mata, sem proporção definida. Posteriormente, é utilizado como substrato na produção de mudas de hortaliças.

De acordo com relato e com a própria utilização do agricultor, o local para a compostagem da mamona deve ser sombreado, amontoando as plantas de mamona e restos de capim colonião (Figura 2B) juntamente ao esterco de aves; o capim e a mamona são recorrentes no local. 


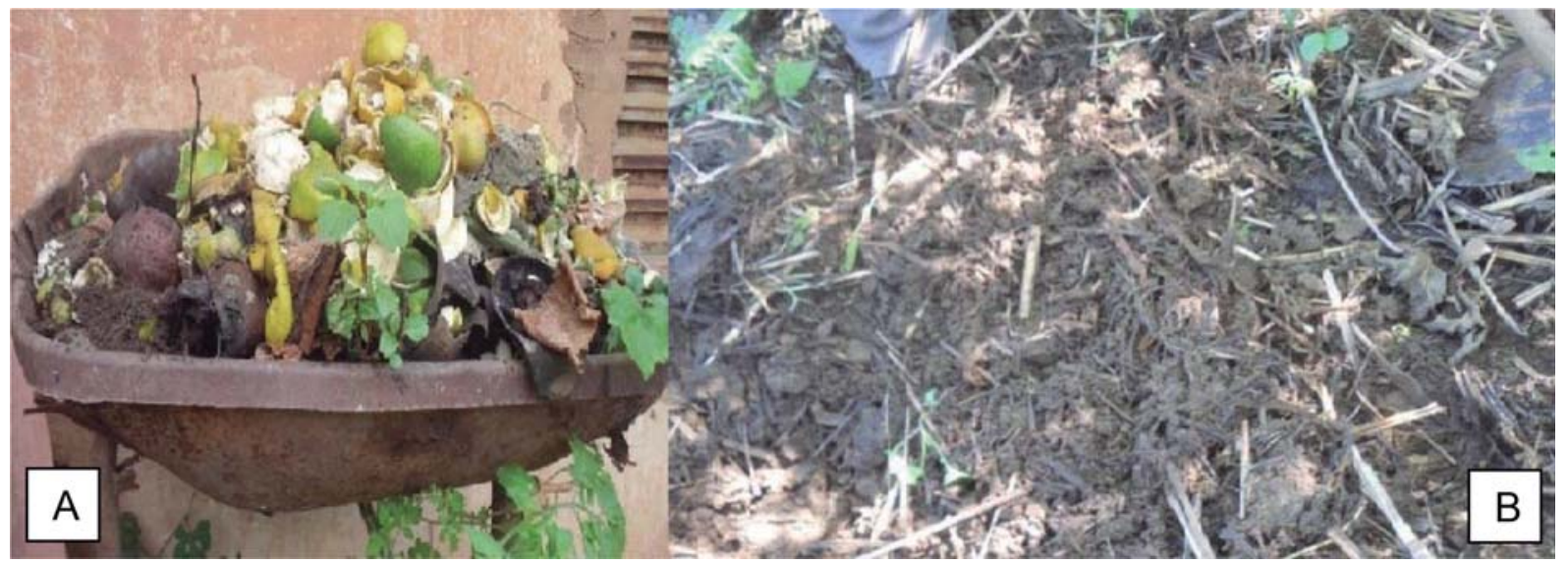

Figura 2 - Composteira da janela da cozinha (A) e compostagem de mamona e capim colonião (B). Assentamento Olga Benário, Visconde Rio Branco-MG.

Fonte: LabGeo.

\section{Compostagem ao pé da planta}

O agricultor faz o corte de capim colonião em picadeira e o adiciona, sem proporção definida, no entorno das fruteiras do seu quintal. Estse material é também adicionado aos berços de plantio de mudas de quiabo, ao pé das plantas com desenvolvimento mais adiantado e em cultivos de milho. O material é adicionado no momento da capina em que, sobre o solo, o agricultor coloca o capim próximo ao pé das plantas. Assim, o processo de compostagem se dá no local. Por isso, diz-se "compostagem ao pé da planta".

\section{Composto Multimistura}

Esta variação da compostagem foi observada no município de Espera Feliz; nela, a agricultora relatou que a ideia de fazer a formulação surgiu a partir de oficinas, intercâmbios e cursos assistidos. A multimistura é realizada com materiais disponíveis na propriedade; são, em geral, restos de culturas cultivadas, tais como hortaliças e lavoura de café. A agricultora mistura um saco de esterco, um saco de cinza, um saco de palha de café, restos de talos, cascas e borra de café proveniente da cozinha. É, então, organizada uma pilha do composto que, por aproximadamente um mês, é revirado; após esse período, o material torna-se pronto para a utilização no plantio de hortaliças.

"A nossa compostagem é um pouco diferente das outras porque nós usamos o que temos, desde restos da cozinha até os restos da horta, faz uma mistura" (Agricultora - Assentamento Padre Jésus, município de Espera Feliz).

\section{Espuma do tacho de caldo de cana}

De acordo com a agricultora, para fazer rapaduras deve-se ferver o caldo de cana. O processo produz uma espuma que, geralmente, é descartada. A agricultora, contudo, acumula estse subproduto em baldes e, após seu resfriamento, agrega-o à pilha de composto formado na horta. Os materiais formadores da pilha de composto são restos de cozinha, tais como talos e cascas. A agrieultora Ela também coloca restos culturais da própria horta.

\section{Conclusões}

Foi possível observar, sistematizar e registrar as práticas desenvolvidas pelos agricultores. Essas práticas podem ser replicadas na íntegra ou em partes. A metodologia e formas de usos relatados, deixam claro que, essencialmente, as tecnologias e inovações implementadas se adéequam à realidade de trabalho e à região. As técnicas desenvolvidas, em muitas ocasiões reelaboradas e aperfeiçoadas, geram impactos positivos sobre a viabilização da produção e, consequente, geração de renda pela comercialização em feiras, mercados locais e mercados institucionais, como o Programa de Aquisição de Alimentos (PAA) e o Programa Nacional da Alimentação Escolar (PNAE). A experiência vivenciada 
revela que a agricultura familiar, frente a problemas como baixa disponibilidade de recursos financeiros e um mercado consumidor pouco consolidado, segue produzindo do modo mais sustentável possível, contribuindo para a manutenção de agroecossistemas agrícolas sustentáveis e perduráveis.

\section{Fontes de Financiamento}

O trabalho aqui apresentado não recebeu apoio financeiro.

\section{Agradecimentos}

Agradecemos, especialmente, a todos e todas as agricultoras familiares que contribuíram com a realização deste trabalho, ao Centro de Tecnologias Alternativas da Zona da Mata, à Rede Raízes da Mata e à Capes pela concessão da bolsa ao primeiro autor.

\section{Referências}

BEHLING, R. S., RAMOS, A, A, B., HAJAR, A. S., FALCÃO, A. S., SCHMIDTKE, F., SILVA, J. R., BERWANGER, L., VEY, R.T., FUNGUETTO, C. I. Compostagem como alternativa a disposição final de resíduos orgânicos domésticos e seu uso na horticultura. Anais. Salão Internacional de Ensino, Pesquisa e Extensão. v.3, n. 3. 2011.

CAMARA, I.G. In: GALINDO LEAL, C.; CAMARA, I.C. (eds). Mata Atlântica: biodiversidade, ameaças e perspectivas. São Paulo: Fundação SOS Mata Atlântica-Conservação Internacional. Belo Horizonte, 2005, p.31-42

COTRIM, D.; DAL SOGLIO, F. K. Análise do processo de Construção do Conhecimento Agroecológico. Ponencia presentada al VIII Congresso Latino Americano de Sociologia Rural, Porto de Galinhas 2010. 19 p.

DEAN, W. A ferro e fogo: a história e a devastação da Mata Atlântica brasileira. Cia das letras, n. 1949, p. 484, 2004.

DIACONO, M.; MONTEMURRO; F. long-term effects of organic amendments on soil fertility. A review.Agronomy for Sustainable Development. 30:401-422, 2010

FIALHO, L. L.; SILVA, W. T. L.; MILORI, D. M. B. P.; SIMÕES, M. L.; MARTIN-NETO, L. Characterization of organic matter from composting of different residues by physicochemical and spectroscopic methods. Bioresource Technology, v.101, p.1927-1934, 2010.

FLORIANI, N.; FLORIANI, D. Saber Ambiental Complexo: aportes cognitivos ao pensamento agroecológico. Revista Brasileira de Agroecologia. Rev. Bras. de Agroecologia, Porto Alegre, 5(1): 323. 2010.

GLIESSMAN, S. R. Agroecologia: processos ecológicos em agricultura sustentável. 4.ed. Porto Alegre: Ed. UFRGS, 2009.

GOLFARI, L. Zoneamento Ecológico do Estado de Minas Gerais para reflorestamento. Série Técnica, 3. CPFRC. Belo Horizonte. BR. 1975.

LEAL, M. A. A.; GUERRA, J. G. M.; PEIXOTO, R. T. G.; ALMEIDA, D. L. Utilização de compostos orgânicos como substratos na produção de mudas de hortaliças. Horticultura Brasileira, v.25, p.392-395, 2007.

LEAL, M. A. A.; GUERRA, ESPINDOLA, J. A. A.; ARAÚJO, E. S. Compostagem de misturas de capim-elefante e torta de mamona com diferentes relações C:N. Revista Brasileira de Engenharia Agrícola e Ambiental. v.17, n.11, p.1195-1200, 2013.

TEIXEIRA, L.B.; GERMANO, V.L.C.; OLIVEIRA, R.F.; FURLAN JR, J. Processo de compostagem a partir do lixo orgânico urbano e caroço de açaí. Circular Técnica, Belém. 2002.

Recebido para publicação em 24/3/2017 e aprovado em 8/6/2017. 